University of Nebraska - Lincoln

DigitalCommons@University of Nebraska - Lincoln

Educational Psychology Papers and

Publications

Educational Psychology, Department of

$11-20-2001$

\title{
The Effects of Conjoint Behavioral Consultation: Results of a 4-Year Investigation
}

\author{
Susan M. Sheridan \\ University of Nebraska-Lincoln, ssheridan2@unl.edu \\ John W. Eagle \\ University of Nebraska-Lincoln \\ Richard J. Cowan \\ University of Nebraska-Lincoln, rcowan1@kent.edu \\ William Mickelson \\ University of Nebraska-Lincoln
}

Follow this and additional works at: https://digitalcommons.unl.edu/edpsychpapers

Part of the Educational Psychology Commons

Sheridan, Susan M.; Eagle, John W.; Cowan, Richard J.; and Mickelson, William, "The Effects of Conjoint Behavioral Consultation: Results of a 4-Year Investigation" (2001). Educational Psychology Papers and Publications. 37.

https://digitalcommons.unl.edu/edpsychpapers/37

This Article is brought to you for free and open access by the Educational Psychology, Department of at DigitalCommons@University of Nebraska - Lincoln. It has been accepted for inclusion in Educational Psychology Papers and Publications by an authorized administrator of DigitalCommons@University of Nebraska - Lincoln. 
Published in Journal of School Psychology, Vol. 39, No. 5 (2001), pp. 361-385. Copyright $\odot$ 2001 Society for the Study of School Psychology; published by Pergamon Press, division of Elsevier Science Ltd. Used by permission.

Submitted August 25, 2000; accepted March 7, 2001.

Correspondence: Susan M. Sheridan, Department of Educational Psychology, 239 Teachers College Hall, University of Nebraska-Lincoln, Lincoln, NE 68588-0345. Email: ssheridan2@unl.edu

\title{
The Effects of Conjoint Behavioral Consultation: Results of a 4-Year Investigation
}

\author{
Susan M. Sheridan, John W. Eagle, \\ Richard J. Cowan, and William Mickelson \\ University of Nebraska-Lincoln
}

\begin{abstract}
Conjoint behavioral consultation $(\mathrm{CBC})$ is a structured indirect form of service delivery in which parents, teachers, and other support staff are joined to work together to address the academic, social, or behavioral needs of an individual for whom all parties bear some responsibility. In this article, outcome data from 4 years of federally funded projects in the area of CBC are presented. Thirty graduate students were trained in CBC and were responsible for providing consultation services to parents and teachers of students with disabilities or at risk for academic failure. Consultation clients included 52 students with disabilities such as behavior disorders, attention-deficit hyperactivity disorder, anxiety, and learning disabilities. The primary research objective concerned assessing the efficacy of CBC across home and school settings. Secondarily, a prediction model was investigated based on client age, case complexity, and severity of symptoms. Perception of effectiveness, process acceptability, and consultee satisfaction with consultants was also investigated. Meaningful effect sizes were yielded across home and school settings. A model fitting client age and symptom severity was found to predict school effect size relatively well. Consultees' perceptions of effectiveness, acceptability of $\mathrm{CBC}$, and satisfaction with consultants were also favorable. Implications of these findings and directions for future research are explored.
\end{abstract}

Keywords: Conjoint behavioral consultations, Home-school partnerships, Outcomes, Effect sizes, Social validity.

The most recent educational reform effort (now public law) is Goals 2000: Educating America Act, which codifies in law eight National Education Goals addressing school readiness, school completion, student academic achievement, professional development of teachers, leadership in math and science, adult literacy, safe and drug-free schools, and parental participation. These goals set the expectation that every child will start school ready to learn and every school will promote partnerships that increase parent participation in facilitating the social, emotional, and academic growth of children (Goals 2000: Educate America Act, 
1994). Goals 1 and 8 explicitly link families and schools, and encourage educators to examine how school policies and practices influence their relationships with families. In particular, Goal 8 states an objective that schools "actively engage parents and families in a partnership which supports the academic work of children at home and shared educational decision making at school" (p. 36).

Among the features of home-school partnerships supported by Goal 8 are (a) a belief in a shared responsibility for educating and socializing children, (b) an emphasis on the quality of interactions among families and school personnel, and (c) a focus on mutually identifying solutions and conditions that support learning and optimal development. These principles are consistent with an ecological-systems approach to development (Bronfenbrenner, 1979) that recognizes the importance of the interface between a child's primary environments (in this case, the home and school) and the role of mesosystemic influences in a child's functioning. Indeed, over 120 studies reviewed by Christenson and Christenson (1998) have reported significant positive correlations between family influences and student learning.

There are many means for parents to support their child's education, and for educators and families to share in the responsibility of supporting children's learning and development. Gains in student performance are greatest when interventions from a mesosystemic orientation (focusing on the reciprocal relationship between home and school) rather than a microsystemic perspective (attending to the classroom or home setting only) are used (Christenson \& Sheridan, 2001). Conjoint behavioral consultation (CBC) offers a structured model that intervenes specifically at the level of the mesosystem to actively engage educators and family members in mutual shared decision making regarding a child's performance.

$\mathrm{CBC}$ is a structured indirect form of service delivery in which parents, teachers, and other support staff are joined to work together to address the academic, social, or behavioral needs of a student (Sheridan \& Kratochwill, 1992; Sheridan, Kratochwill, \& Bergan, 1996). It is designed to engage significant consultees from various systems in a collaborative problem-solving process. In this model, the interconnections between systems are considered essential in the development and implementation of effective programs for students. As such, CBC exemplifies a model of partnerships for children wherein school psychologists can be proactive in working with parents, teachers, and other professionals to promote conditions that enhance student success. Specifically, it is expected that conjoint problem-solving meetings may improve the communication and interactions between the child, family, and school personnel. Likewise, it is hoped that $\mathrm{CBC}$ can promote joint and shared responsibility (i.e., across both home and school) for problem solution.

Details of CBC theory, procedure, and research are available in Sheridan et al. (1996). Briefly, the model is structured around four problem-solving stages 
involving problem-solving interviews between a consultant, parent(s), and teacher(s): problem identification, problem analysis, treatment implementation, and treatment evaluation. It should be noted that although the model follows a stagewise progression, it is generally fluid and cyclical in practice.

The effectiveness of CBC has received empirical scrutiny through various studies, and single subject research to date indicates that $\mathrm{CBC}$ is effective for certain behavioral, academic, and affective difficulties of students (see Sheridan, 1997, and Sheridan et al., 1996, for reviews of CBC research). In at least two studies, results indicated that $\mathrm{CBC}$ was superior to other forms of service delivery including teacher-only consultation (Sheridan, Kratochwill, \& Elliott, 1990) and self-training manuals (Galloway \& Sheridan, 1994). For boys with attentiondeficit hyperactivity disorder (ADHD), Colton and Sheridan (1998) reported increases in positive cooperative play behaviors resulting from the implementation of a CBC-mediated behavioral social skills intervention. Weiner, Sheridan, and Jenson (1998) implemented the model with parents and teachers of 5 middle school students at risk of failing their respective mathematics requirements. In this study, the authors reported increases in homework completion and accuracy among the majority of students during $\mathrm{CBC}$, with gains maintained at follow-up. To date, however, no large-scale study has evaluated the efficacy of $\mathrm{CBC}$ in naturalistic field settings.

Although several studies using small $N$ methodology have demonstrated positive effects on global and behavioral measures, no research has explored the relationship among relevant case variables and outcomes. Among the possible factors that might contribute to $\mathrm{CBC}$ effects are age of the child being served, complexity of the case (i.e., number of target behaviors), and severity of symptoms as reported by care providers.

Age of client served is an important issue in consultation research. Little empirical research has investigated the effects of consultation with students beyond the elementary level. Although early-intervention research advocates for collaborative indirect services for primary care providers, there currently lacks a consistent knowledge base in this area. Likewise, research is replete with findings of decreased parental involvement when children leave the elementary school system and enter secondary settings (Epstein \& Connors, 1995). In addition, little is known about the effects of consultation with students in secondary educational institutions (i.e., middle and high schools; Weiner et al., 1998).

Little research has been conducted evaluating whether case complexity or the severity of behavioral symptoms impact the outcome of consultation. Acceptability researchers have hypothesized that these factors contribute to consumers' perceptions of the acceptability of interventions designed to address referral concerns (e.g., Elliott, 1988; Reimers, Wacker, \& Koeppl, 1987). Specifically, complexity is thought to have an inverse relationship to treatment acceptability, whereby the more complex an intervention, the less acceptable to the consultee. 
However, when behavioral symptoms are considered severe, treatment agents are thought to find interventions generally more acceptable than when symptoms are less problematic. It is possible that similar relationships are apparent between complexity, severity, and treatment effects; however, these relationships have not been investigated through empirical research.

At least two survey studies investigated the acceptability of $\mathrm{CBC}$ among various participants (i.e., school psychologists, teachers, and parents). In a study assessing perceptions of a national sample of school psychologists, Sheridan and Steck (1995) found that practitioners endorse the practice readily, reporting extremely favorable acceptability of the procedures overall. Whether considering its use with academic, behavioral, or social-emotional problems, school psychologists consistently rated $\mathrm{CBC}$ significantly more acceptable than teacher-only or parent-only consultation. Furthermore, similarly higher relative ratings were found for CBC when compared with other forms of consultation for school psychologists practicing in elementary and secondary schools. Years of experience and level of training (specialist vs. doctoral) were not found to be significant predictors of acceptability. Taken together, these findings suggested that across problems, age of students served, and practitioners, CBC was perceived as a highly acceptable procedure.

Freer and Watson (1999) furthered the work of Sheridan and Steck (1995) by assessing the acceptability of CBC among parents and teachers. Using similar instruments and procedures, these authors also found $\mathrm{CBC}$ to be more acceptable than parent-only or teacher-only consultation. Specifically, for academic, behavioral, and social-emotional problems, both parents and teachers selected CBC as the most preferred consultation approach. Likewise, in terms of overall acceptability, parents and teachers rated $\mathrm{CBC}$ as the most acceptable form of consultation.

Although the majority of outcome studies described earlier included acceptability and other social validity measures with a small number of participants (e.g., Colton \& Sheridan, 1998; Galloway \& Sheridan, 1994; Weiner et al., 1998), there are no large-scale studies assessing the degree of acceptability of CBC to participants who actually engaged in specific applications of the model. Sheridan and Steck (1995) and Freer and Watson (1999) assessed participants' subjective perceptions of acceptability without actually participating in the CBC process (i.e., "hypothetical acceptability"). Such survey research often lacks ecological validity and suffers from problems with potential bias. There is a need for research investigating participants' acceptability of the $\mathrm{CBC}$ process and procedures as a function of their in vivo experiences.

\section{PURPOSE OF STUDY}

The purposes of the study were to assess the effects of CRC on dimensions of objective outcomes and social validity, and to analyze potential predictive relationships between case variables and behavioral outcomes. Primary research ques- 
tions were (a) What are the general effects of $\mathrm{CBC}$ when used to support students with disabilities or who are at risk due to academic, behavioral, or social difficulties? (b) What are the setting-specific (home-school) effects for behavioral, academic, and social targets? (c) Are predictive relationships evident between client age, case complexity, symptom severity, and behavioral outcomes? (d) How do parents and teachers perceive $\mathrm{CBC}$ in terms of its perceived effectiveness and acceptability? and (e) How satisfied are parents and teachers with $\mathrm{CBC}$ consultants and services?

\section{METHODS}

\section{Participants}

Participants in this study included 52 students with disabilities or at risk for academic failure. The 52 students were involved in a total of $57 \mathrm{CBC}$ cases (i.e., for 4 of the students, full-scale CBC case procedures were implemented for more than one problem behavior), yielding a total of 66 effect sizes. ${ }^{1}$ The students' parents $(n=53)$ and teachers $(n=56)$, and 30 graduate student consultants were also involved. Demographic information for all participants was collected on self-report forms administered at the beginning of each consultation case. Parents reported demographic information for their children.

Child participants. Consultation clients included 52 students in kindergarten through the ninth grade. Seventy-four percent of clients were diagnosed or classified with an academic or behavioral-emotional disorder. Of these, $32 \%$ were classified as learning disabled, $32 \%$ were classified as behavior disordered, $14 \%$ were classified as intellectually handicapped, $11 \%$ were diagnosed with ADHD, and an additional $11 \%$ were diagnosed with nonspecified or other disorders (e.g., Asperger's). Twenty-six percent of the sample did not have a formal educational classification or psychiatric diagnosis, but were considered "at risk" due to academic, behavioral, or social difficulties that were interfering with their educational progress. Referrals to CBC consultants were made primarily by school psychologists, special education teachers, or other multidisciplinary team members. Students were identified by these school staff as individuals struggling to meet basic academic requirements or demonstrating inappropriate behaviors or chronic social-emotional difficulties that interfered with their performance. For students without a formal educational classification, CBC services were provided as a prereferral intervention strategy.

\footnotetext{
${ }^{1}$ For some clients, behavioral data were collected on more than one related target (e.g., work completion and work accuracy). In such circumstances, all data were collected in the context of one CBC procedure rather than instituting the four-stage model for each target. Thus, numbers in Table 1 do not correspond to the number of cases presented in the narrative.
} 
Sixty-seven percent of child participants were male, and 33\% were female. Students' grade levels ranged from kindergarten to Grade 9, with a mean grade of 3.8. The mean age of clients was 9.4 years. Of the child clients, $43 \%$ lived in single-parent households and $10 \%$ of their mothers had not completed high school. Seventy-seven percent were Caucasian, $10 \%$ were Hispanic, and the remainder were African American, Native American, Chinese, or biracial. Eight percent spoke a language other than English in the home. Twenty-two percent lived in households that were considered to be of low socioeconomic status, with an annual household income of less than $\$ 15,000$.

Parents. Parents of child subjects also served as consultee participants in this study. Eighty percent of the parent consultees were mothers, and $29 \%$ were fathers. In $71 \%$ of the cases, only mothers were involved as parent consultees. In $20 \%$ of the cases, only fathers were involved. Nine percent of the cases involved both parents. The average age of parent participant was 37 years. Of the parents, $84 \%$ of parents were Caucasian and $16 \%$ were non-White (note that this is generally representative of the population in the state where the study occurred).

Teachers. Teachers were also involved as consultee participants in this study. The majority was female (86\%) and Caucasian (96\%). Sixty-one percent had a bachelor's as their highest degree, and 37\% held a master's degree. The average number of years of experience was 11.7. The mean age was 43 years. Eightynine percent of the teachers instructed in general education classrooms, which is consistent with the emphasis on inclusion in this study. In at least six cases, a special education teacher and/or an interpreter were also involved.

Consultants. Consultants in the study were 30 graduate students in school psychology who were trained to mastery in the procedural implementation of CBC. Of these, $53 \%$ were in a doctoral training program and $47 \%$ were in a master's program at the same university. The mean age of consultants was 31 years. Seventy-seven percent of the consultants were female; $23 \%$ were male. Eighty-seven percent were Caucasian; $13 \%$ were from an ethnically diverse background.

Thirty-seven percent reported that they had prior experience providing consultation services, but none had provided $\mathrm{CBC}$ services prior to their involvement in the program. The average number of cases completed by consultants was 1.86 (range 1-5). Sixteen of the 30 consultants completed two CBC cases, and 10 completed one case. The remaining four consultants completed between three and five cases each. 


\section{Setting}

Consultation cases were conducted across four school districts in a large western city and its suburbs. The majority of consultation interviews were held in teachers' classrooms. Interventions were conducted in clients' homes and schools.

\section{Outcome Measures}

Case outcomes were evaluated on a number of dimensions. The primary outcome measures involved direct observations of target behaviors in naturalistic settings. Along with direct behavioral data, supplementary social validity data (i.e., subjective evaluation of outcomes, perceptions of goal attainment, and ratings of acceptability and satisfaction) were collected for each case to address additional research questions. Social validation, or the meaningfulness or relevance of treatment effects, is an important variable that has taken on considerable importance in applied intervention and consultation studies (Gresham \& Noell, 1993; Kazdin, 1977; Kratochwill, 1985).

Direct observations. Direct observations of student (client) performance served as primary outcome measures. Specific target behaviors were identified for each student, and direct behavioral measures were collected continuously by parents and teachers throughout all experimental phases (i.e., baseline, treatment, and follow-up). Data collection forms (i.e., Behavioral Records) were provided to consultees to (a) standardize the observational procedures; (b) provide an opportunity to train consultees in data collection procedures; and (c) encourage a permanent record of data.

Subjective evaluation of outcome. Consultees' subjective perceptions of case outcomes were assessed as one form of social validity. Parents' and teachers'subjective beliefs of treatment efficacy were assessed on a revised version the Behavior Intervention Rating Scale (BIRS; Von Brock \& Elliott, 1987). The BIRS consists of 24 items rated on a 6-point Likert scale. Factor analysis of the BIRS has yielded three factors: Acceptability, Effectiveness, and Time to Effect (Elliott \& Von Brock Treuting, 1991). In a study assessing the reliability and construct validity of the BIRS, Von Brock and Elliott (1987) reported alpha coefficients of .97 for the total scale, and $.97, .92$, and .87 for the Acceptability, Effectiveness, and Time to Effect factors, respectively. An analysis of the internal consistency of the revised BIRS total scale based on the present sample yielded alpha coefficients of $r=.95$ for teachers and $r=.93$ for parents.

The BIRS Effectiveness factor is comprised of 7 items scored on a 6-point Likert scale ( $1=$ low perceived efficacy; $6=$ high perceived efficacy). Minor revisions of the BIRS's original wording made the instrument applicable to consultation procedures while still maintaining psychometric soundness (Freer \& Watson, 1999; Sheridan \& Steck, 1995). For the present sample, alpha coefficients of 
$r=.95$ were found for both teacher and parent Effectiveness scales. Parents and teachers completed the revised BIRS in its entirety following their final Conjoint Treatment Evaluation Interviews (CTEI) as part of a "final perceptions" form (described in Procedures).

Perception of goal attainment. Goal Attainment Scaling (GAS; Kiresuk, Smith, \& Cardillo, 1994) procedures provided a second form of social validity. GAS was used to assess parents' and teachers' perceptions of attainment of consultation goals. Following consultation, parents and teachers reported the degree to which they believed consultation goals were met using a scale of -2 (situation got significantly worse) to +2 (goal completely met).

Excellent reviews of the reliability and validity of GAS procedures are available in Cardillo and Smith (1994) and Smith and Cardillo (1994), respectively. Studies that used a 5-point scale (similar to the approach used herein) reported interrater reliability indices between $r=.87$ (Kaplan \& Smith, 1977) and $r=.93$ (Schippits \& Baxter, 1978 as cited in Cardillo \& Smith, 1994). Analyses of testretest reliability yielded product moment correlations of $r=.84$ over a 2- to 3week period (Woodward, Santa-Barbara, Levin, \& Epstein, 1978). There is also evidence of criterion-related (Jacobs \& Cytrynbaum, 1977) and construct validity (e.g., Johnson \& Greenberg, 1985).

Ratings of acceptability. Parents' and teachers' acceptability of CBC (process acceptability) was assessed with the Acceptability factor of the BIRS. Fifteen items comprise the Acceptability factor, with items scored on a 6-point Likert scale $(1=$ not at all acceptable; $6=$ highly acceptable). Evidence of reliability and validity of this scale are available in Elliott and Von Brock Treuting (1991). An analysis of the internal consistency of the revised BIRS Acceptability scale based on the present sample yielded alpha coefficients of $r=.94$ for teachers and $r=.86$ for parents.

Ratings of satisfaction with CBC services. A fourth form of social validation concerned "consumer satisfaction," or consultees' satisfaction with the consultant and CBC services. The Consultant Evaluation Form (CEF; Erchul, 1987) was used to assess consultee satisfaction. The CEF is a 12-item 7-point Likert scale that measures the degree to which consultees found consultants helpful. Parents and teachers completed the CEF after their CTEI. Early research with the $\mathrm{CEF}$ has yielded adequate internal consistency estimates (alpha $=.95$; Erchul, 1987). For the present sample, alpha coefficients of $r=.83$ and $r .89$ were found for teacher and parent scales, respectively.

\section{PROCEDURES}

Data from this study were derived from 4 years of federally funded training grants for which the first author was principal investigator. Over the 4-year 
period, 30 school psychology graduate students were trained to mastery in the principles and procedures of $\mathrm{CBC}$ using competency-based training methods. Participation of the graduate students was voluntary, although they received a modest stipend for their involvement. Detailed information regarding the competency-based training model is beyond the scope of this article. Interested readers are referred to Kratochwill, Elliott, and Busse (1996), Kratochwill, Sheridan, Carrington Rotto, and Salmon (1992), and Sheridan (1992) for demonstrations of similar models.

As part of their involvement on the training grant, graduate students enrolled in an advanced consultation seminar and practicum. The practicum utilized competency-based training procedures to train students in CBC to a mastery level of performance (defined as meeting an average of $85 \%$ of $\mathrm{CBC}$ interview objectives, assessed by supervisors on CBC Objectives Checklists). Following demonstration of mastery, graduate students were placed in elementary and middle schools in a large western city. In their placements, they were responsible for providing consultation services to parents and teachers of students with disabilities who were being served in the mainstream environment under an inclusion pattern of service.

CBC cases followed a four-stage problem-solving model including problem identification, problem analysis, plan implementation, and plan evaluation (Bergan \& Kratochwill, 1990; Kratochwill \& Bergan, 1990). As an extension of the behavioral consultation procedure, $\mathrm{CBC}$ involved parents and teachers as joint consultees in all cases (i.e., consultation occurred with parents and teachers serving as co-consultees in the same meetings). The stages were initiated via structured interview procedures using formats available in the published literature (Sheridan et al., 1996).

All cases were audiotaped for supervision and evaluation purposes. A structured supervision model developed initially by Sheridan, Salmon, Kratochwill, and Carrington Rotto (1992) was used. Supervision of each interview was conducted by the first author or by advanced graduate students previously trained and experienced in providing $\mathrm{CBC}$ services.

Referrals for consultation were initiated in various ways. In some cases, consultants met with school-based teams or certified school psychologists who identified appropriate cases [i.e., students who were classified under special education law and were receiving some instruction in the mainstream educational setting, those who did not meet criteria for an educational classification but still required classroom or curricular modifications (e.g., children diagnosed with ADHD), or those who were at risk for failing to meet academic requirements in the general classroom]. In a small number of other cases, referrals were initiated by parents who were familiar with the $\mathrm{CBC}$ project. Upon referral, consultants scheduled meetings [i.e., preconsultation meetings or Conjoint Problem Identification Interviews (CPII)], obtained written consent from parents and teachers, and proceeded with consultation services. 
Prior to initiating $\mathrm{CBC}$, consultants held preconsultation meetings with parents and teachers. The purposes of these meetings included meeting the parents and teachers, establishing a climate of shared ownership and home-school partnership, initiating a relationship between the parent and teacher and between the consultant and consultees, sharing information about $\mathrm{CBC}$ procedures, establishing basic agreement about roles and responsibilities of parties, and obtaining parental and teacher consent for participation. Likewise, general information about the child's strengths, and the concerns and priorities of both parents and teachers was discussed. Finally, teacher, parent, and client demographic information forms were given to parents and teachers on which information about background characteristics was recorded.

Target behaviors selected for consultation, assessment, and intervention were identified collaboratively by parents, teachers, and consultants during CPIIs. Consistent with $\mathrm{CBC}$ procedures, consultees provided information on the nature of problems that were of primary concern, and consultants worked with them to operationally define target behaviors during CPIIs. Target behaviors were defined as either behaviors to decrease or alternative behaviors to increase. Baseline data collection procedures were also discussed during this consultation interview.

Procedures for conducting direct observations were reviewed with parents and teachers in the CPIIs. Specifically, appropriate recording techniques employing event, latency, duration, or interval procedures were reviewed. Informal training in the use of the relevant technique occurred in the way of discussion, written documentation, and standard observation forms. Consultants checked with consultees at least once during the baseline data collection period to answer questions and monitor observational procedures. Similar checks on data collection were made during the treatment implementation stage.

During the Conjoint Problem Analysis Interviews (CPAI), consultants and consultees analyzed the baseline data, attempted to identify conditions surrounding their occurrence, and developed a behavioral intervention. Virtually all cases included behavioral interventions implemented by parents and/or teachers within the context of CBC. All behavioral interventions relied on positive reinforcement principles; some included additional components such as skill training or environmental manipulations.

Interventions were implemented across settings during the treatment implementation stage. Although no formal interview occurred during treatment implementation, consultants maintained contacts with consultees via classroom visits and telephone calls. Finally, CTEIs were conducted at the end of each case to discuss progress toward consultation goals, required modifications to treatment plans, and the need for future consultation. In all cases, at least two CTEIs were conducted to allow for plan revision and re-evaluation.

Following the final CTEI, consultees were administered Final Perceptions Checklists (Sheridan \& Erchul, 1995). Information related to frequency of 
meetings, referral arrangements, and reason for consultation termination was collected on these forms. In addition, several outcome instruments were reproduced on the forms, including the CEF (Erchul, 1987), the BIRS (Von Brock \& Elliott, 1987), and GAS (Kiresuk et al., 1994). Consultees were provided with postage paid envelopes addressed to the primary investigator in which to return the forms.

Reports were written for each case to summarize case information and referral concerns, details of the intervention, data collected continuously throughout baseline and treatment conditions, outcomes of the CBC-based interventions across home and school, and recommendations for follow-up or future intervention. Information in reports was derived from standard consultation interview forms, direct observations, Behavioral Records, and Treatment Plan Worksheets.

\section{Integrity of CBC Process}

Across the 57 cases, there were 230 CBC interviews ( $M=4$ per case). Of these, 19 were either inaudible or missing from the dataset (e.g., some interviews were not taped due to recorder malfunction or other unavoidable circumstances). One hundred percent of the remaining 211 audiotaped interviews (92\% of total interviews conducted) were coded by observers to assess the degree to which consultants followed $\mathrm{CBC}$ procedures with integrity. Observers were individuals trained in $\mathrm{CBC}$ by the primary author who had completed the $\mathrm{CBC}$ training program in a previous year, and who had met criteria for mastery of $\mathrm{CBC}$ procedures in practice (i.e., role play) settings. Coders listened to audiotapes of the interviews and completed $\mathrm{CBC}$ Objectives Checklists on which specific $\mathrm{CBC}$ objectives were recorded for each interview. The checklists were summaries of $\mathrm{CBC}$ objectives as listed on the CBC structured interview forms (Sheridan et al., 1996) adapted from Behavioral Consultation Objectives Checklists used in previous research (Kratochwill et al., 1992; Sheridan, 1992).

\section{Integrity of Interventions}

Treatment integrity of consultation-derived interventions across home and school was determined in one of two ways. First, in many cases, intervention plans were recorded on Treatment Plan Worksheets to provide a written summary of the general plan strategy, document specific plan steps, request selfmonitoring of the plan's implementation, and otherwise encourage integrity of treatment plan. implementation by parents and teachers. Consultees who selfrecorded completion of any of the steps of the treatment plan were credited for providing some evidence of fidelity. Second, in some cases, evidence of treatment integrity was determined by reviewing aspects of behavioral programs that yielded permanent products (e.g., sticker charts, contracts, home notes, self- 
monitoring sheets). Although these are recognized as very liberal and imprecise measures of treatment integrity, they nevertheless yielded some gross data on parents' and teachers' adherence to at least some aspects of behavioral plans.

\section{Coding of Data}

Data from demographic information forms, final perceptions forms, Behavioral Records, Treatment Plan Worksheets, and case reports were entered into a spreadsheet software program by three research assistants (graduate students in school psychology) trained by the first author over a 4-year period. In addition, over the course of the project, frequent checks for accuracy were made by the second author, with corrections made to the computerized dataset as necessary. At project termination, four observers (graduate students in school psychology) were trained in the data content, organization, and entry by the second author. Twenty-four percent of all data in the computer spreadsheet was checked by the observers to assess interrater reliability. Interrater reliability between the spreadsheet and the reliability observers was $98.7 \%$, suggesting a high degree of accuracy in the 4-year $\mathrm{CBC}$ dataset.

\section{Data Analysis}

The primary outcome data reported herein reflect mean single subject effect sizes derived from individual case data. ${ }^{2}$ Various small $N$ designs were used to evaluate the effectiveness of interventions implemented in the context of the $\mathrm{CBC}$ cases across settings. Due to individual differences across homes and schools, some cases utilized slightly different designs across settings. In both settings, the largest majority of designs employed controlled case study (A/B) procedures (Kazdin, 1982; Kratochwill, 1985). Specifically, 76\% of the cases at school and $72 \%$ at home utilized A/B designs to determine outcomes. Multiple baseline designs were used in $14 \%$ of the cases at school and $20 \%$ of the cases

\footnotetext{
${ }^{2}$ Presentation of mean effect sizes was preferred over statistical tests for several reasons. First, some assumptions for inferential statistics were violated in our dataset (e.g., independence of observations, equal variances). Second, we believed that hypothesis testing would not adequately address our research questions pertaining to general effectiveness and acceptability of CBC (Olejnik \& Hess, 1997); that is, our concern was whether CBC produced an effect and, if so, the magnitude of the effect, rather than whether there was a difference between experimental and control conditions or whether there was a functional relation between independent and dependent variables (Chow, 1988). It has been suggested by several noteworthy statisticians (Carver, 1978; Chow, 1988; Levin, 1998; Robinson \& Levin, 1997) that effect sizes are the indices that provide information about the importance of a difference or relationship, and are more informative than knowledge that a statistical test is significant (Chow, 1988). Specifically, these indices (rather than those derived from statistical tests) provide information on magnitude of results in relation to sample size and error. Therefore, we have chosen to report the actual magnitude of the difference (effect sizes) and confidence intervals to acknowledge sampling error (Levin, 1998).
} 
at home. Multitreatment designs (Tawney \& Gast, 1984) were used in $7 \%$ of the cases at school and $8 \%$ at home. An additional $3 \%$ of school cases employed a reversal design. Finally, $7 \%$ of the cases at school and $20 \%$ at home investigated the maintenance of treatment effects through the use of a follow-up phase. Visual analysis procedures were used to monitor student responsiveness to interventions and to evaluate case outcomes. The presentation of individual client data is beyond the scope of this article. Rather, single subject effect sizes, confidence intervals, and descriptive results from rating scales and subjective evaluations are presented.

Effect sizes for each case were computed using a "no assumptions" approach (Busk \& Serliri, 1992) that computes effects without assumptions regarding population distributions or homogeneity of variance. In this approach, the differences in phase means within a given case is divided by the standard deviation of the baseline, which produces a quantitative index of treatment effects. The vast majority of cases yielded effect sizes in both home and school settings, so separate mean single subject effect sizes by setting are reported. Mean single-subject effect sizes for behavioral, academic, and social targets are also presented. Effect sizes of +1 or more indicate that the effect size is similar to one standard deviation above the expected baseline mean. According to Cohen (1992), an effect size of 0.2 is considered small, an effect size of 0.5 is medium, and an effect size of 0.8 is large.

To further understand the aggregate results, $95 \%$ confidence intervals on the average effect sizes were computed. Confidence intervals present a range of values within which the "true" average effect size of a particular setting or condition is likely to lie (Kirk, 1996). The upper and lower limits of the interval provide useful information of the magnitude of the difference. Further, the width of the interval (i.e., the difference between the upper and lower limits) provides an indication of the precision with which the mean effect sizes is estimated. The narrower the interval, the more precise the estimate. It should be noted that smaller sample sizes yield wider confidence intervals (Chow, 1988).

To examine the relationship between client age, case complexity, symptom severity, and the behavioral effect size outcomes, a multiple regression analysis was conducted separately for each setting (i.e., home and school). Client age was determined based on parent report of the child's age in years. Case complexity was defined as the number of target behaviors addressed across home and school settings (i.e., the more behaviors targeted in consultation, the more complex the case). For purposes of the regression analyses, a dichotomous variable (dummy coded) was established consisting of one target (not complex) or two or more targets (complex). Symptom severity was defined as the sum of severity ratings provided by parents and teachers prior to the initiation of $\mathrm{CBC}$ services. Specifically, each parent and teacher provided a pre-CBC rating of the severity of the 
referral concern (i.e., target behavior) on a scale of 1 (less severe) to 7 (more severe). For the regression analysis, a composite severity variate was constructed, based on the sum of independent parent and teacher ratings. The analysis proceeded by examining the interaction between complexity and severity, as well as the interaction between complexity and client age.

Social validity data assessing subjective impressions of efficacy and goal attainment, CBC acceptability, and consumer satisfaction were evaluated descriptively.

\section{RESULTS}

\section{Case Outcomes}

Average single subject effect sizes across home and school settings are presented in Table 1. Data in the table summarize 66 individual client effect sizes. Across all cases, effect sizes ranged from -0.36 to 7.08 , with an average effect size of $1.10(S D=1.07)$. Home and school effect sizes were approximately equal. Home-based targets yielded an average effect size of $1.08(S D=0.82)$. Schoolbased targets yielded an average effect size of $1.11(S D=1.24)$. Taken together, these findings suggest that the average case outcome at both home and school is in the desired direction by slightly more than one standard deviation above what could be expected based on the baseline mean. According to Cohen (1992), this constitutes a large effect size and can be considered of practical significance, as well as statistical significance.

To better understand outcome expectations associated with $\mathrm{CBC}$, confidence levels and intervals were computed (see Table 1). Across all cases, the confidence interval on the average effect size was 0.83 to 1.36 , suggesting that the

Table 1

Mean Effect Sizes and Confidence Intervals by Setting

\begin{tabular}{lccc}
\hline & Home & School & Overall \\
\hline$n$ & 28 & 38 & 66 \\
ES & 1.08 & 1.11 & 1.10 \\
$S E$ & 0.16 & 0.20 & 0.13 \\
$S D$ & 0.82 & 1.24 & 1.07 \\
Mm & -0.27 & -0.36 & -0.36 \\
Max & 3.21 & 7.08 & 7.08 \\
CI & $0.76-1.39$ & $0.70-1.52$ & $0.83-1.36$ \\
\hline
\end{tabular}

$\mathrm{ES}=$ average effect size within category; $S E=$ standard error; $S D=$ standard deviation; $\mathrm{Mm}$ $=$ minimum effect size value within category; Max = maximum effect size value within category; $\mathrm{Cl}=$ confidence interval based on confidence level of $95 \%$. 
"true" population average effect size related to $\mathrm{CBC}$ implementation is contained within this range with $95 \%$ confidence. As can be seen in the table, effect sizes within the confidence intervals are all positive (i.e., above zero).

\section{Effects of Age, Case Complexity, and Symptom Severity}

A multiple linear regression approach was utilized in an effort to examine the relationships between client age, case complexity, severity of symptoms, and individual effect sizes. Separate analyses were conducted for the home and school settings. The regression model included the three predictor variables (client age, case complexity, and symptom severity), along with terms for the interaction of age with complexity, age with severity, and complexity with severity.

In the analysis of the school effect sizes, case complexity along with all interaction terms that included case complexity was not statistically significant. A model fitting client age and symptom severity, however, was found to predict school effect size relatively well $\left(R^{2}=.425\right.$, Adjusted $\left.R^{2}=.343\right)$, with significance level for the overall regression model being $p=.008$. Although the regression coefficients can be interpreted individually, the overall model can also be interpreted in general and used to make predictions. The predictive model associated with this multiple regression is

$$
\begin{gathered}
\mathrm{ES}=\beta_{0}+\beta_{1} \times \text { Severity }+\beta_{2} \times \text { Age }+\beta_{3} \times \text { Severity } \times \text { Age } \\
\text { ES }=-5.406+0.741 \times \text { Severity }+0.575 \times \text { Age }-0.0686 \times \text { Severity } \times \text { Age }
\end{gathered}
$$

Interpreting this equation indicates that the older client with less severe symptoms or the younger client with more severe symptoms would be predicted to experience higher effect sizes due to $\mathrm{CBC}$ intervention. On the other hand, the older client with severe symptoms would have a much smaller predicted effect size. Data are not available to comment on the effect of $\mathrm{CBC}$ on younger clients with less severe symptoms.

To further illustrate the regression result for school effect size, the continuous age and severity variables were re-coded into categorical variables. For the severity composite variable (defined as the sum of parent and teacher severity ratings), scores of 6 and less were considered low, whereas values of 11 or larger were considered high. Table 2 presents descriptive statistics for this categorization. Figure 1 is a profile plot of the mean level of effect size relative to the categorization of the age and severity variables. From the summarized data and profile plot, the significant interaction from the regression analysis is clearly evident.

In the analysis of the home effect size, the multiple regression model utilizing client age, symptom severity, and symptom complexity along with interaction terms resulted in a nonstatistically significant regression model $(p=.698)$. Fur- 
Table 2

Descriptive Statistics on School Effect Sizes for Age and Severity of Symptom

\begin{tabular}{|c|c|c|c|c|c|c|}
\hline \multirow[b]{3}{*}{ Age of Client } & \multicolumn{6}{|c|}{ Symptom Severity } \\
\hline & \multicolumn{2}{|c|}{ Low } & \multicolumn{2}{|c|}{ Medium } & \multicolumn{2}{|c|}{ High } \\
\hline & M & (SD) & M & (SD) & M & (SD) \\
\hline 5 to 7 years & \multicolumn{2}{|c|}{ No Data } & \multicolumn{2}{|c|}{$\begin{array}{c}1.277 \begin{array}{c}(0.503) \\
(n=3)\end{array}\end{array}$} & \multicolumn{2}{|c|}{$\begin{array}{c}2.325 \quad(0.841) \\
(n=2)\end{array}$} \\
\hline 8 to 10 years & \multicolumn{2}{|c|}{$\begin{array}{c}0.090 \\
(n=2)\end{array}$} & \multicolumn{2}{|c|}{$(n=5)$} & & $(n=5)$ \\
\hline 11 years and older & 1.19 & $\begin{array}{l}(0.431) \\
4)\end{array}$ & 0.347 & $\begin{array}{l}(0.542) \\
\text { 2) }\end{array}$ & 0.665 & $\begin{array}{l}(0.417) \\
2)\end{array}$ \\
\hline
\end{tabular}

$\mathrm{M}=$ Average case effect size at school.

thermore, the overall measure of model fit was extremely low $\left(R^{2}=.079\right)$. In this analysis, client age, symptom severity, and symptom complexity were not predictive of home effect sizes.

\section{Social Validity}

Social validity measures were included as an important concern in this study, given its applied field-based nature. Assessment of consultees' subjective evaluations of outcomes, goal attainment, acceptability, and satisfaction were included within a framework of social validation.

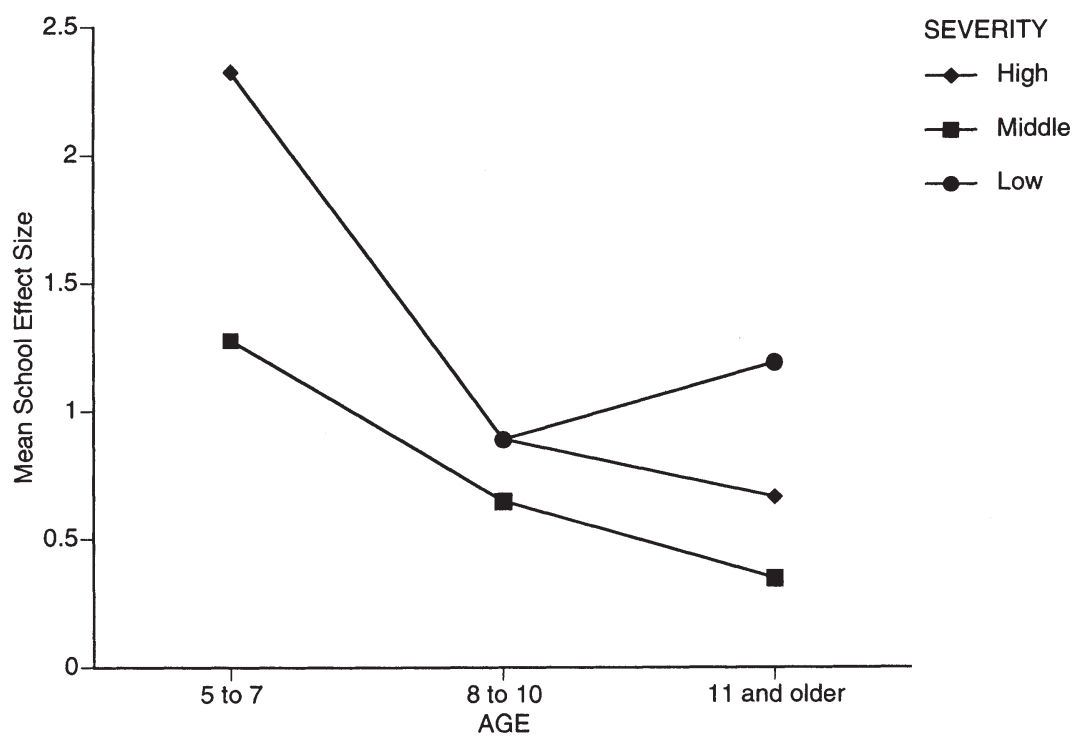

Figure 1. Profile plot of mean school effect size by severity and age of client, 
Parents' and teachers' subjective evaluation of outcomes was assessed on the Effectiveness factor of the BIRS. Whereas teachers' mean item ratings on this factor averaged $4.30(S D=1.3)$ out of a possible total score of 6.0, parents tended to rate the process as slightly more effective (mean item rating = 4.71; $S D=0.95$ ). Reports on GAS measures (Kiresuk et al., 1994) also indicated that both parents and teachers considered the goals established in consultation to have been attained. An overwhelming majority reported that the goals were partially or fully met (100\% of parents and $94 \%$ of teachers, respectively).

Ratings on the Acceptability factor of the BIRS (Von Brock \& Elliott, 1987) also demonstrated that $\mathrm{CBC}$ was a highly acceptable process. Specifically, out of a possible score of 6.0, parents' mean item ratings of the acceptability of CBC yielded an average of $5.44(S D=0.52)$ and teachers' mean item ratings averaged $5.45(S D=0.60)$. Parents and teachers also reported high levels of satisfaction with the consultant and the consultation experience, as measured by the CEF (Erchul, 1987). Teacher ratings of satisfaction, averaging 6.35 (SD = 0.63 ) out of a possible 7.0, were slightly higher than parents' ratings that averaged $6.22(S D=0.88)$.

\section{Integrity of CBC and Interventions}

Two forms of integrity were evaluated in this study. Integrity with which consultants completed CBC cases per the structured protocol (Sheridan et al., 1996) was assessed via review of audio recordings of all interviews. Observers trained in $\mathrm{CBC}$ by the primary author listened to audiotapes of the interviews and completed CBC Objectives Checklists (summaries of CBC objectives as listed on the CBC structured interview forms; Sheridan et al., 1996). Across all consultants and interviews, an average of $83 \%$ of the objectives were met, suggesting generalization of the training objectives to field-based casework. Specifically, consultants collectively met $82 \%$ of the objectives for CPII, $83 \%$ for CPAI, and $80 \%$ for CTEI.

Integrity of consultation-derived interventions across home and school was determined through either consultee self-report data on Treatment Plan Worksheets, or by evidence of intervention-related permanent products (e.g., stickers on charts, points on home-notes). If any evidence was available that any aspect of the intervention was implemented by consultees, credit for some fidelity was given. Using these very liberal criteria, $71 \%$ of all CBC-derived treatment plans had some documentation of implementation integrity.

\section{DISCUSSION}

The preliminary analyses presented here suggest that $\mathrm{CBC}$ is a generally effective model of service delivery across home and school settings. Furthermore, consultees' perceptions of CBC are consistently positive as evidenced by their 
subjective ratings of efficacy, acceptability, and satisfaction. In addition, parent and teacher ratings indicate high overall satisfaction with school psychologists as consultants. This research corroborates previous research that provided support for CBC with socially withdrawn children (Sheridan et al., 1990), academically underachieving primary grade students (Galloway \& Sheridan, 1994), boys with ADHD and social skills deficits (Colton \& Sheridan, 1998), and middle school students failing in math (Weiner et al., 1998). It also supports the acceptability survey research on CBC, in which school psychologists (Sheridan \& Steck, 1995) and parents and teachers (Freer \& Watson, 1999) rated the procedures in analog assessments as highly acceptable. In essence, CBC represents an expanded role of school psychologists (e.g., Sheridan \& Gutkin, 2000) as consultants and educational team members in proactive prereferral problem solving to promote the rights of individual students and families mandated in IDEA Amendments of 1997 (1997; see Sheridan, Cowan, \& Eagle, 2000).

The magnitude of average effect sizes reflected in this 4-year study, ranging from 1.08 to $1.11(M=1.10, S D=1.07)$, is promising. These results are consistent with previous research in related areas. Other behavioral consultation researchers have reported effect sizes of 1.36 (Reddy, Barboza-Whitehead, Files, \& Rubel, 2000) and 0.96 (Busse, Kratochwill, \& Elliott, 1999). In a meta-analysis of interventions addressing disruptive classroom behavior for other behavioral and mental health treatments, Stage and Quiroz (1997) reported an overall effect size of -0.78 , which is a positive outcome suggesting fewer classroom disruptions as a function of intervention. Finally, psychotherapy researchers have found effect sizes of 0.54 (Weisz, Weiss, Han, Granger, \& Morton, 1995), 0.71 (Casey \& Berman, 1985), 0.79 (Weisz, Weiss, Alicke, \& Klotz, 1987), and 0.88 (Kazdin, Bass, Ayers, \& Rodgers, 1990).

This large-scale study of CBC serves to further the knowledge base in the area of home-school partnerships. Many contemporary definitions emphasize shared educational decision making (Goals 2000: Educating America Act, 1994), bidirectional communication (Swap, 1993), and the development of a constructive relationship (Christenson \& Sheridan, 2001; Pianta \& Walsh, 1996) in promoting the academic and social development of children and youth. Aspects of these definitional principles are inherent in CBC. Stated process goals of the model include increasing understanding of family members and school personnel, promoting shared ownership across systems for problem solution, and strengthening relationships among participants (Sheridan et al., 1996). Verbal and nonverbal strategies are used by $\mathrm{CBC}$ consultants to support these goals (e.g., reframing, using minimal encouragers, acknowledging different perspectives, reinforcing joint attendance at interviews, commenting on instances of congruence or incongruence across settings or expectations). Although research to date has not yet investigated the presence or absence of these consultant strategies in $\mathrm{CBC}$ interviews or the effect of $\mathrm{CBC}$ on the home-school partnership, a great deal of anec- 
dotal information supports the notion that relationships across home and school can be greatly enhanced through this process. Through dialogue and shared problem solving, parents and teachers may co-construct new ways of supporting the learner (Henning Stout, personal communication, February, 2001). In this way, and consistent with ecological systems theory (Bronfenbrenner, 1977), it is possible that the active and constructive interactions among family members and school personnel in CBC form a unique subsystem in the child's life. The extent and mechanisms by which process and outcome are related is unknown. Clearly, research is needed to understand the effects of $\mathrm{CBC}$ on the home-school relationship and other mesosystemic influences, and the manner in which these relate to behavioral outcomes.

Regression analyses suggest that at school, older clients with less severe symptoms and younger clients with more severe symptoms (based on composite severity ratings of parents and teachers) experienced high effect sizes. This may be explained, in part, by the developmental trajectory of children's problems over time. It is possible that parent and teacher interventions aimed at remediating target problems rated as severe are more effective with younger children (below age 11) than with older children and adolescents (over age 11). However, when older children exhibit less severe problems, CBC-based interventions can still be expected to yield effective outcomes. In fact, school effect sizes with younger children exhibiting target problems rated as very severe were very promising. This finding attests to the benefits of the model when implemented early in a child's school life, and supports literature identifying the benefits of establishing meaningful parent-teacher relationships at an early age (Pianta \& Walsh, 1996). It is possible that early partnerships may establish a pathway toward school success for children, including those whose problems are rated as severe by parents and teachers. Although the current research does not provide conclusive evidence of CBC's contribution to such pathways, future research may investigate the effects of the model with children exhibiting severe symptomatology using a longitudinal design. The degree to which $\mathrm{CBC}$ can circumvent future problems from occurring or serve as a prevention model represents an extension of these findings worthy of focused investigation.

Although the results of $\mathrm{CBC}$ cases appear promising based on effect sizes, some caution must be exercised when interpreting these results. First, there is a great deal of variability evident in the effect sizes (as indicated by an average standard deviation of 1.07). Second, the precision of the estimates is questioned in some cases. Although overall confidence intervals suggested that high effect sizes could be expected a majority of the time, the confidence interval range was great, particularly at school.

Taken together, the findings of the regression analysis and the variability in results across cases yield several important implications for practice and research. First, CBC can be expected to be effective with many clients presenting 
a range of problems, but perhaps not equally so. At school, older students presenting less severe symptoms fared better than those with more severe presenting problems, and younger students with greater levels of problem severity demonstrated greater treatment gains. Although clients demonstrated variable outcomes based on objective measures, parents and teachers seemed to find the procedures generally acceptable and effective. It seems that consultees' ratings of acceptability and effectiveness are based on dimensions other than objective outcomes. It is not clear what forms the basis of these consultee ratings, or which specific dimensions of $\mathrm{CBC}$ they find acceptable or effective (e.g., problem solving discussions, opportunities for dialogue, improved relationship, feelings of support). Future research should use designs that allow for the sophisticated analysis of consumers' perspectives of the model.

The potential role of $\mathrm{CBC}$ in enhancing family process variables is also worthy of attention. Coined "the curriculum of the home" (Walberg, 1984), familyrelated interventions such as those aimed at enhancing communication, increasing structure, providing learning opportunities, and modeling high but realistic academic expectations within home environments may prove useful when implemented within the context of CBC. For example, helping families increase structure in the morning routine and ensure that children are well rested and nourished before coming to school may be appropriate targets of intervention. Given that a child's physical well-being may serve as a setting event for learning and behavior at school, information obtained through CBC that allows for these variables to be addressed are a relevant part of the consultant's repertoire. Generally speaking, conceptualizing $\mathrm{CBC}$ as a conduit for aiding parents in identifying ways that they can provide enrichment opportunities and enhance the curriculum of the home seems worthwhile.

\section{Limitations of Current Research}

Although the present findings provide encouraging evidence of CBC's efficacy, some limitations are apparent. First, direct outcome data are derived from information provided by parents and teachers, with no reliability data collected or reported. Some minimal data collection training took place in selected cases, but there was no way of ensuring consistent data collection in natural settings. Additionally, direct observational data were not reported for all cases.

A second limitation concerns the fact that the information collected on treatment integrity is extremely limited. Integrity of intervention procedures is a critical area in need of careful attention (Gresham, 1989; Lentz, Allen, \& Ehrhardt, 1996; Noell, Witt, Gilbertson, Ranier, \& Freeland, 1997). In this study, consultees were asked to self-monitor their implementation of intervention steps, and these self-report or other permanent product data are available for approximately $71 \%$ of cases. However, these procedures provide only gross measures 
of integrity, with no understanding of relative levels with which consultees adhered to treatment plans. Furthermore, the degree to which intervention components were implemented accurately, reliably, or completely is unknown. All that can be concluded is that at least some elements of the treatments appear to have been implemented in approximately $70 \%$ of the cases. Without systematic data on intervention integrity, conclusions regarding the degree to which consultation interventions were responsible for the effects are premature. Procedures for reliably and objectively assessing treatment integrity in large-scale behavioral consultation and $\mathrm{CBC}$ research are needed. Furthermore, research must investigate the relationship between integrity and outcomes because this aspect of behavioral intervention effects is not clearly known.

A final limitation in this study concerns the lack of external validity of these $\mathrm{CBC}$ case procedures. All consultants were trained by the first author, in the context of an intensive year-long advanced seminar and practicum sequence. The cases included in this study represent ideal practice situations wherein graduate students devoted several hours over consecutive weeks, systematically assessing behavioral concerns, monitoring treatment effects, planning for generalization, and evaluating outcomes. It is unlikely that practitioners in the field would be exposed to such extensive training and supervision in $\mathrm{CBC}$, or have the opportunity to devote so many hours to its implementation. Methods to infuse CBC procedures into practice in a feasible, efficient, and effective manner are necessary.

\section{CONCLUSIONS}

CBC has been suggested as a feasible model by which family members and school personnel can join together to address shared concerns regarding the academic, behavioral, or social needs of a student. Previous studies have investigated and supported its efficacy with a small number of students. The current study has furthered the empirical base by determining the effects of CBC when implemented with several cases across a large sample. In general, the findings were positive; moderate to large effect sizes were found across home and school settings. The present investigation offers general support of $\mathrm{CBC}$, although a great deal of variability was evident, and treatment effects were more promising with some clients than with others and with target concerns of varying degrees of severity.

It is believed that $\mathrm{CBC}$ can be a useful tool to school practitioners who strive to forge partnerships between homes and schools. School psychologists, parents, and teachers have suggested acceptance of the model in survey research, and current results suggest that consumers (parents and teachers) report high levels of acceptance and satisfaction toward the process. Strategies to incorporate CBC into the widespread practice of school psychologists may be worthy of pursuit. 


\section{ACKNOWLEDGMENTS}

Research described in this article was supported by federal grants awarded to the first author by the U.S. Department of Education, Office of Special Education and Rehabilitative Services. The statements and opinions contained herein belong to the authors and are not reflective of the granting agency. The authors would like to acknowledge Denise Colton, Jaqui Richard, Tracine Smoot, and the several parents, teachers, and students who all contributed greatly to the completion of this study. Special thanks are extended to William P. Erchul for his help in the early conceptualization and development of materials used in this study.

\section{REFERENCES}

Bergan, J. R., \& Kratochwill, T. R. (1990). Behavioral consultation in applied settings. New York: Plenum.

Bronfenbrenner, U. (1977). Toward an experimental ecology of human development. American Psychologist, 32, 513-529.

Bronfenbrenner, U. (1979). The ecology of human development. Cambridge, MA: Harvard University Press.

Busk, P. L., \& Serlin, R. C. (1992). Meta-analysis for single-case research. In T. R. Kratochwill \& J. R. Levin (Eds.), Single-case research design and analysis: Applications in psychology and education (pp. 187-212). Hillsdale, NJ: Erlbaum.

Busse, R. T., Kratochwill, T. R, \& Elliott, S. N. (1999). Influences of verbal interactions during behavioral consultation on treatment outcomes. Journal of School Psychology, 37, 117-143.

Cardillo, J. E., \& Smith, A. (1994). Reliability of goal attainment scores. In T. J. Kiresuk, A. Smith, \& J. E. Cardillo (Eds.), Goal attainment scaling: Applications, theory, and measurement (pp. 213-242). Hillsdale, NJ: Erlbaum.

Carver, R. P. (1978). The case against statistical significance testing. Harvard Educational Review, 48, 378-399.

Casey, R.J., \& Berman, J. S. (1985). The outcome of psychotherapy with children. Psychological Bulletin, 98, 388-400.

Chow, S. L. (1988). Significance test or effect size? Psychological Bulletin, 103, 105-110,

Christenson, S. L., \& Christenson, C. J. (1998). Family, school, and community influences on children's learning: A literature review (Report No. 1). Live and learn project. Minneapolis, MN: University of Minnesota Extension Service.

Christenson, S. L., \& Sheridan, S. M. (2001). Schools and families: Creating essential connections for learning. New York: Guilford Press.

Cohen, J. (1992). A power primer. Psychological Bulletin, 112, 155-159.

Colton, D., \& Sheridan, S. M. (1998). Conjoint behavioral consultation and social skills training: Enhancing the play behavior of boys with attention deficit-hyperactivity disorder, Journal of Educational and Psychological Consultation, 9, 3-28.

Elliott, S. N. (1988). Acceptability of behavioral treatments: Review of variables that influence treatment selection. Professional Psychology: Research and Practice, 19, 68-80. 
Elliott, S. N., \& Von Brock Treuting, M. (1991). The Behavior Intervention Rating Scale: Development and validation of a pretreatment acceptability and effectiveness measure. Journal of School Psychology, 29, 43-51.

Epstein, J. L., \& Connors, L. (1995). School and family partnerships in the middle grades. In B. Rutherford (Ed.), Creating family/school partnerships (pp. 137-166). Columbus, $\mathrm{OH}$ : National Middle School Association.

Erchul, W. P. (1987). A relational communication analysis of control in school consultation. Professional School Psychology, 2, 113-124.

Freer, P., \& Watson, T. S. (1999). A comparison of parent and teacher acceptability ratings of behavior and conjoint behavioral consultation. School Psychology Review, 28, 672-684.

Galloway, J., \& Sheridan, S. M. (1994). Implementing scientific practices through case studies: Examples using home-school interventions and consultation. Journal of School Psychology, 32, 385-413.

Goals 2000: Educating America Act. (1994) Pub. L No. 103-227.

Gresham, F. M. (1989). Assessment of treatment integrity in school consultation and prereferral intervention. School Psychology Review, 18, 37-50.

Gresham, F. M., \& Noell, G. H. (1993). Documenting the effectiveness of consultation outcomes. In J. E. Zins, T. R. Kratochwill, \& S. N. Elliott (Eds.), Handbook of consultation services for children (pp. 249-273). San Francisco: Jossey-Bass.

IDEA Amendments of 1997. (1997) Pub. L. No. 105-117.

Jacobs, S., \& Cytrynbaum, S. (1977). The goal attainment scale: A test of its use on an inpatient crisis intervention unit. Goal Attainment Review, 3, 77-98.

Johnson, S. M., \& Greenberg, L. S. (1985). Differential effects of experiential and problemsolving interventions in resolving marital conflict. Journal of Consulting and Clinical Psychology, 53, 175-184.

Kaplan, J. M., \& Smith, W. G. (1977). The use of attainment scaling in the evaluation of a regional mental health program. Community Mental Health Journal 13, 188-193.

Kazdin, A. E. (1977). Assessing the clinical or applied importance of behavior change through social validation. Behavior Modification, 1, 427-452.

Kazdin, A. E. (1982). Single-case research designs: Methods for clinical and applied settings. New York: Oxford University Press.

Kazdin, A. E., Bass. D., Ayers, W. A., \& Rodgers, A. (1990). Empirical and clinical focus of child and adolescent psychotherapy research. Journal of Consulting and Clinical Psychology, 58, 729-740.

Kiresuk, T. J., Smith, A., \& Cardillo, J. E. (Eds.). (1994). Goal attainment scaling: Applications, theory, and measurement. Hillsdale, NJ: Erlbaum.

Kirk, R. E. (1996). Practical significance: A concept whose time has come. Educational and Psychological Measurement, 56, 746-759.

Kratochwill, T. R. (1985). Case study research in school psychology. School Psychology Review, 14, 204-215.

Kratochwill, T. R, \& Bergan, J. R. (1990). Behavioral consultation in applied settings: An individual guide. New York: Plenum.

Kratochwill, T. R., Elliott, S. N., \& Busse, R. T. (1996). Behavior consultation: A five-year evaluation of consultant and client outcomes. School Psychology Quarterly, 10, 87-117. 
Kratochwill, T. R., Sheridan, S. M., Carrington Rotto, P. J., \& Salmon, D. (1992). Preparation of school psychologists to serve as consultants for teachers of emotionally disturbed children. School Psychology Review, 20, 530-550.

Lentz, F. E., Allen, S. J., \& Ehrhardt, K. E. (1996). The conceptual elements of strong interventions in school settings. School Psychology Quarterly, 11, 118-136.

Levin, J. R. (1998). To test or not to test $H_{0}$ ? Educational and Psychological Measurement, $58,313-333$.

Noell, G. H., Witt, J. C., Gilbertson, D. N., Ranier, D. D., \& Freeland, J. T. (1997). Increasing teacher intervention implementation in general education settings through consultation and performance feedback. School Psychology Quarterly, 12, 77-88.

Olejnik, S., \& Hess, B. (1997). Top ten reasons why most omnibus ANOVA F-tests should be abandoned. Journal of Vocational Education Research, 22, 219-232.

Pianta, R., \& Walsh, D. B. (1996). High risk children in schools: Constructing sustaining relationships. New York: Routledge.

Reddy, L.A., Barboza-Whitehead, S., Files, T., \& Rubel, E. (2000). Clinical focus of consultation outcome research with children and adolescents. Special Services in the Schools, $16,1-22$.

Reimers, T. M., Wacker, D. P., \& Koeppl, G. (1987). Acceptability of behavioral interventions: A review of the literature. School Psychology Review, 16, 212-227.

Robinson, D. H., \& Levin, J. R. (1997). Reflections on statistical and substantive significance, with a slice of replication. Educational Researcher, 26, 21-26.

Schippits, H., \& Baxter, J. W. (1978). Tightening the hitch: An update on "hitch your treatment to a goal." Paper presented at Adult Psychiatric Day Treatment: 2nd Multi-Disciplinary National Forum, Minneapolis, MN.

Sheridan, S. M. (1992). Consultant and client outcomes of competency-based behavioral consultation training. School Psychology Quarterly, 7, 245-270.

Sheridan, S. M. (1997). Conceptual and empirical bases of conjoint behavioral consultation. School Psychology Quarterly, 12, 119-133.

Sheridan, S. M., Cowan, R.J., \& Eagle, J. W. (2000). Partnering with parents in educational programming for students with special needs, In C. Telzrow \& M. Tankersley (Eds.), IDEA Amendments of 1997: Practice guidelines for school-based teams (pp. 307-349). Bethesda, MD: National Association of School Psychologists.

Sheridan, S. M., \& Erchul, W. P. (1995). Consultee final perceptions form. Unpublished scale. Salt Lake City, UT: University of Utah; and Raleigh, NC: North Carolina State University.

Sheridan, S. M., \& Gutkin, T. B. (2000). The ecology of school psychology: Examining and changing our paradigm for the 21st Century. School Psychology Review, 29, 485-502.

Sheridan, S. M., \& Kratochwill, T. R. (1992). Behavioral parent-teacher consultation: Conceptual and research considerations. Journal of School Psychology, 30, 117-139.

Sheridan, S. M., Kratochwill, T. R., \& Bergan, J. R. (1996). Conjoint behavioral consultation: A procedural manual. New York: Plenum.

Sheridan, S. M., Kratochwill, T. R., \& Elliott, S. N. (1990). Behavioral consultation with parents and teachers: Delivering treatment for socially withdrawn children at home and school. School Psychology Review, 19, 33-52. 
Sheridan, S. M., Salmon, D., Kratochwill, T. R., \& Carrington Rotto, P. J. (1992). A conceptual model for the expansion of behavioral consultation training. Journal of Educational and Psychological Consultation, 3, 193-218.

Sheridan, S. M., \& Steck, M. (1995). Acceptability of conjoint behavioral consultation: A national survey of school psychologists. School Psychology Review, 24, 633-647.

Smith, A., \& Cardillo, J. E. (1994). Perspectives on validity. In T. J. Kiresuk, A. Smith, \& J. E. Cardillo (Eds.), Goal attainment scaling: Applications, theory, and measurement (pp. 243-272). Hillsdale, NJ: Erlbaum.

Stage, S. A., \& Quiroz, D. R. (1997). A meta-analysis of interventions to decrease disruptive classroom behavior in public education settings. School Psychology Review, 26, 333-368.

Swap, S. M. (1993). Developing home-school partnerships: From concepts to practice. New York: Teachers College Press.

Tawney, J. W., \& Gast, D. L. (1984). Single subject research in special education. Columbus, $\mathrm{OH}$ : Merrill.

Von Brock, M. B., \& Elliott, S. N. (1987). Influence of treatment effectiveness information on the acceptability of classroom interventions, Journal of School Psychology, 25, 131-144.

Walberg, H. J. (1984). Families as partners in educational productivity. Phi Delta Kappan, 65, 397-400.

Weiner, R., Sheridan, S. M., \& Jenson, W. R. (1998). Effects of conjoint behavioral consultation and a structured homework program on math completion and accuracy in junior high students. School Psychology Quarterly, 13, 281-309.

Weisz, J. R., Weiss, B., Alicke, M. D., \& Klotz, M. L. (1987). Effectiveness of psychotherapy with children and adolescents: A meta-analysis for clinicians. Journal of Consulting and Clinical Psychology, 55, 542-549.

Weisz, J. R., Weiss, B., Han, S. S., Granger, D. A., \& Morton, T. (1995). Effects of psychotherapy with children and adolescents revisited: A meta-analysis of treatment outcome studies. Psychological Bulletin, 117, 450-468.

Woodward, C. A., Santa-Barbara, J., Levin, S., \& Epstein, N. (1978). The role of Goal Attainment Scaling in evaluating family therapy outcome. American Journal of Orthopsychiatry, 48, 464-476. 